\title{
Degradation, Bioactivity, and Osteogenic Potential of Composites Made of PLGA and Two Different Sol-Gel Bioactive Glasses
}

\author{
Elzbieta Pamula, ${ }^{1}$ Justyna Kokoszka, ${ }^{2}$ Katarzyna Cholewa-Kowalska, ${ }^{2}$ Maria Laczka, ${ }^{2}$ \\ Lukasz Kantor,${ }^{3}$ Lukasz Niedzwiedzki, ${ }^{4}$ Gwendolen C. Reilly, ${ }^{5}$ Joanna Filipowska, ${ }^{6}$ \\ Wojciech Madej, ${ }^{6}$ Malgorzata Kolodziejczyk, ${ }^{6}$ Grzegorz Tylko, ${ }^{6}$ and Anna M. Osyczka ${ }^{6}$ \\ ${ }^{1}$ Department of Biomaterials, Faculty of Materials Science and Ceramics, AGH-University of Science and Technology, \\ Mickiewicza Ave. 30, 30-059 Krakow, Poland; ${ }^{2}$ Department of Glass Technology and Amorphous Coatings, Faculty of \\ Materials Science and Ceramics, AGH-University of Science and Technology, Mickiewicza Ave. 30, 30-059 Krakow, Poland; \\ ${ }^{3}$ Multidisciplinary School of Engineering in Biomedicine, AGH-University of Science and Technology, Mickiewicza Ave. 30, \\ 30-059 Krakow, Poland; ${ }^{4}$ Department of Orthopedics and Musculoskeletal Traumatology, Institute of Physiotherapy, \\ Faculty of Health Care, School of Medicine, Jagiellonian University, Michalowskiego 12, 31-126 Krakow, Poland; \\ ${ }^{5}$ Department of Materials Science and Engineering, University of Sheffield, The Kroto Research Institute, Broad Lane, \\ Sheffield S3 7HQ, UK; and ${ }^{6}$ Department of Cell Biology and Imaging, Faculty of Biology and Earth Sciences, Jagiellonian \\ University, Ingardena 6, 30-060 Krakow, Poland
}

(Received 27 October 2010; accepted 28 March 2011; published online 13 April 2011)

Associate Editor Kent Leach oversaw the review of this article.

\begin{abstract}
We have developed poly(L-lactide-co-glycolide) (PLGA) based composites using sol-gel derived bioactive glasses (S-BG), previously described by our group, as composite components. Two different composite types were manufactured that contained either S2- high content silica S-BG, or A2- high content lime S-BG. The composites were evaluated in the form of sheets and 3D scaffolds. Sheets containing 12,21 , and $33 \mathrm{vol} . \%$ of each bioactive glass were characterized for mechanical properties, wettability, hydrolytic degradation, and surface bioactivity. Sheets containing A2 S-BG rapidly formed a hydroxyapatite surface layer after incubation in simulated body fluid. The incorporation of either S-BG increased the tensile strength and Young's modulus of the composites and tailored their degradation rates compared to starting compounds. Sheets and 3D scaffolds were evaluated for their ability to support growth of human bone marrow cells (BMC) and MG-63 cells, respectively. Cells were grown in non-differentiating, osteogenic or osteoclast-inducing conditions. Osteogenesis was induced with either recombinant human BMP-2 or dexamethasone, and osteoclast formation with M-CSF. BMC viability was lower at higher S-BG content, though specific ALP/cell was significantly higher on PLGA/A2-33 composites. Composites containing S2 S-BG enhanced calcification of extracellular matrix by $\mathrm{BMC}$, whereas incorporation of A2 S-BG in the composites promoted osteoclast formation from BMC. MG-63 osteoblast-like cells seeded in porous scaffolds containing S2 maintained viability and secreted collagen and calcium throughout the scaffolds. Overall, the
\end{abstract}

Address correspondence to Anna M. Osyczka, Department of Cell Biology and Imaging, Faculty of Biology and Earth Sciences, Jagiellonian University, Ingardena 6, 30-060 Krakow, Poland. Electronic mail: a.m.osyczka@uj.edu.pl presented data show functional versatility of the composites studied and indicate their potential to design a wide variety of implant materials differing in physico-chemical properties and biological applications. We propose these sol-gel derived bioactive glass-PLGA composites may prove excellent potential orthopedic and dental biomaterials supporting bone formation and remodeling.

Keywords-Bioactive glass, Sol-gel method, Poly(L-lactideco-glycolide), Bioactive composites, Bone morphogenetic proteins, Human bone marrow cells, MG-63 cells, Alkaline phosphatase, Mineralization, Osteoclasts.

\section{INTRODUCTION}

Current treatments of bone defects include the use of autografts, allografts, and artificial biomaterials. ${ }^{2}$ The availability of auto- and allografts continues to be limited by supply, donor-site morbidity, the risk of immune rejection and infections and, often, high costs. ${ }^{15}$ Orthopedic implants made of artificial materials offer an alternative to supply the growing needs for bone replacement therapies. Beyond the widely recognized titanium implants, the latter can be made of bioresorbable polymers (e.g., polylactides, polyglycolide, and their copolymers) and/or bioactive ceramics (e.g., hydroxyapatite, tricalcium phosphate, bioactive glasses, glass ceramics). Poly(L-lactideco-glycolide) (PLGA) is among the few synthetic polymers approved for human clinical use because of 
good biocompatibility, controllable degradability, and relatively good processability. PLGA has been used as scaffolds for bone tissue engineering ${ }^{32}$ and for drug delivery purposes, including delivery of growth factors and hormones involved in bone regeneration. ${ }^{34}$ However, the polymer itself is bioinert and does not elicit a biological response in bone cells. ${ }^{23}$ Bioactive materials such as bioactive glass, on the other hand, promote attachment, growth, and osteogenic differentiation of progenitor cells in vitro and are capable of forming interfacial bonds with bone tissue in vivo. ${ }^{13}$

Combining polymers and bioactive glass into composites is a relatively new concept in bone tissue engineering and the benefits of such composites include: (1) enhanced mechanical properties enabling better integration with bone tissue, ${ }^{26}$ (2) enhanced bioactivity promoting new bone formation, ${ }^{4}$ and (3) tailored degradation rates allowing the body's own bone to heal, grow, remodel, and eventually replace the graft materials. ${ }^{25}$ Specifically, incorporation of bioactive glass into a polymer base has been shown to delay the degradation rate of the polymer compared to the neat polymer foam, ${ }^{25}$ enhance the composite's bioactivity, ${ }^{4}$ improve the processing of porous poly(L-lactide)/bioactive glass composites ${ }^{44}$ and improve the mechanical properties of these composites. ${ }^{26,28}$ Several approaches employed biodegradable polymers and the melt-derived 45S5 Bioglass ${ }^{\circledR}$ developed by Hench $^{8,22,39,42,43}$ but very few reports applied sol-gel derived bioactive glass instead. ${ }^{24}$ In general, gel-derived bioactive glasses have a larger surface area and $\mathrm{OH}$ groups are present in their structure. Thus, their bioactivity is usually higher than bioactive glasses prepared by melting. Consequently, they may stimulate faster regeneration in living bone. Our earlier studies reported the production, physico-chemical, and biological properties of gel-derived bioactive glasses of the $\mathrm{CaO}-\mathrm{P}_{2} \mathrm{O}_{5}-\mathrm{SiO}_{2}$ system. ${ }^{19,27}$ We showed that $\mathrm{CaO}: \mathrm{SiO}_{2}$ ratio in these glasses influenced their physical and chemical properties and affected the growth and differentiation of bone marrow-derived cells. ${ }^{6,17,20}$ Our data further indicate that incorporation of these gel-derived glasses into a HA matrix enhanced growth and osteogenic differentiation of human mesenchymal stem cells (MSC). ${ }^{5}$ Recently, Wu et al. ${ }^{41}$ suggested that PLGA-based composites prepared with a sol-gel derived mesoporous bioactive glass possess advantageous mechanical and biological properties compared to those containing non-mesoporous bioactive glass. Mesoporous, gel-derived bioactive glasses (MBG) have a highly ordered structure and generally higher bioactivity than non-mesoporous bioactive glass obtained by melting. MBG/PLGA films have been characterized by excellent physicochemical, biological, and drug release properties and have been processed into $3 \mathrm{D}$ scaffolds suitable for bone tissue engineering. ${ }^{41}$

In this work we have employed either silica-rich (S2) or calcium-rich (A2) bioactive glasses derived from a basic $\mathrm{CaO}-\mathrm{P}_{2} \mathrm{O}_{5}-\mathrm{SiO}_{2}$ system and obtained by a sol-gel method, to prepare PLGA-based composites. These composites were prepared in the form of sheets and 3D scaffolds and evaluated for their mechanical properties, bioactivity and the ability to enhance BMP2 mediated human bone marrow cell osteogenesis, support osteoclast formation from human bone marrow and osteogenic gene expression of MG-63 osteoblastic cells.

\section{MATERIALS AND METHODS}

\section{Materials}

PLGA was synthesized via a ring opening process in the presence of low toxicity zirconium acetylacetonate as a copolymerization initiator. ${ }^{11}$ The molar ratio of L-lactide to glycolide in the copolymer was $85: 15$ (as studied by ${ }^{1} \mathrm{H}$ NMR), and molecular masses of PLGA were: $M_{\mathrm{n}}=80 \mathrm{kDa}$ and $M_{\mathrm{w}}=152 \mathrm{kDa}$. Bioactive glasses ( $\mathrm{S} 2$ and $\mathrm{A} 2$ ) of the composition of: $\mathrm{S} 2$ : $80 \mathrm{~mol} \% \mathrm{SiO}_{2}-16 \mathrm{~mol} \% \mathrm{CaO}-4 \mathrm{~mol} \% \mathrm{P}_{2} \mathrm{O}_{5}$, and $\mathrm{A} 2$ : $40 \mathrm{~mol}^{\%} \quad \mathrm{SiO}_{2}-54 \mathrm{~mol} \% \mathrm{CaO}-6 \mathrm{~mol} \% \quad \mathrm{P}_{2} \mathrm{O}_{5}$, were produced using the sol-gel method. ${ }^{19}$ Tetraethoxysilane (TEOS; $\left.\mathrm{Si}\left(\mathrm{OC}_{2} \mathrm{H}_{5}\right)_{4}\right)$, triethylphosphate (TEP; $\left.\mathrm{OP}\left(\mathrm{OC}_{2} \mathrm{H}_{5}\right)_{3}\right)$, and calcium nitrate tetra-hydrate $\left(\mathrm{Ca}\left(\mathrm{NO}_{3}\right)_{2} \cdot 4 \mathrm{H}_{2} \mathrm{O}\right)$ were used as base components to start the sol-gel process. $\mathrm{HCl}$ solution was used as a catalyst for the hydrolysis and condensation reactions. The formed gel was dried at $40-120^{\circ} \mathrm{C}$ for 7 days and then subjected to thermal treatment at $700{ }^{\circ} \mathrm{C}$ for $20 \mathrm{~h}$. Afterwards it was milled to obtain a bioactive glass powder with particle sizes $<50 \mu \mathrm{m}$.

\section{Composite Sheets Fabrication}

The PLGA-bioactive glass composites were fabricated by mixing glass particles with $10 \% \mathrm{w} / \mathrm{v}$ PLGA solution in methylene chloride on a magnetic stirrer for $3 \mathrm{~h}$, followed by partial evaporation of the solvent in air, slip casting of the viscous mixture on glass Petri dishes, then drying in air and vacuum to a constant weight. The volume fraction of bioactive glass in the composites was 12,21 , and $33 \%$. The composite sheets obtained were $0.11 \mathrm{~mm}$ thick.

\section{Composite Scaffolds Fabrication}

$3 \mathrm{D}$ scaffolds were obtained by addition of sodium chloride (grain fraction $320-400 \mu \mathrm{m}$ ) into the 
copolymer-bioactive glass solution in methylene chloride. The amount of sodium chloride provided $85 \%$ porosity. $\mathrm{NaCl}$ particles were mixed with the PLGA-SBG suspension with the use of spatula until most of the methylene chloride had evaporated. The dense suspension was tightly packed into polypropylene cylindrical vials $(12 \mathrm{~mm}$ in diameter, volume $5 \mathrm{~mL})$, dried in air for $24 \mathrm{~h}$ and then in vacuum conditions for $48 \mathrm{~h}$. Then the vials with the rigid salt/PLGA-S-BG mixture were cut into slices of the thickness of $3 \mathrm{~mm}$ and extensively washed in ultra-high quality water (UHQwater, produced by UHQ-PS purification system, Elga, UK). The water was exchanged several times until the conductivity of the water was about $2 \mu \mathrm{S} / \mathrm{cm}$. Subsequently the samples were air-dried and then vacuumdried for at least $24 \mathrm{~h}$.

\section{Material Evaluation}

The mechanical properties of the sheets, i.e., tensile strength, Young's modulus, and elongation at break of the PLGA-bioactive glass composites were determined with the use of an universal testing machine (Zwick 1435, Germany) and compared to pure PLGA sheets. The parallel specimen length was set to $40 \mathrm{~mm}$, the specimen width was $5 \mathrm{~mm}$, the pre-load force was $0.1 \mathrm{~N}$, the test speed was $100 \mathrm{~mm} / \mathrm{min}$ and six samples were evaluated from each experimental group.

Wettability was evaluated by water contact angle measurements. The contact angle was determined by sessile drop method by an automatic drop shape analysis system DSA $10 \mathrm{Mk} 2$ (Kruss, Germany). UHQ-water droplets of $0.2 \mu \mathrm{L}$ were applied on each sample and the contact angle was calculated by averaging 10 measurements.

To study hydrolytic degradation, the composites, and reference samples (PLGA, S2, and A2) weighing $0.15 \mathrm{~g}$ were placed in separate plastic vials and incubated in $30 \mathrm{~mL}$ UHQ-water at $37^{\circ} \mathrm{C}$ for 3 months. The evaluation was performed according to international standard (ISO 10993-13). ${ }^{16}$ Hydrolytic degradation process was monitored by $\mathrm{pH}$ and conductivity measurements of incubation medium with the use of pH meter (CP-315 Elmetron, Poland) and conductometer (CC-315, Elmetron, Poland), respectively.

The arithmetical mean roughness ( $\mathrm{Ra}$ ) and tenpoint mean roughness depth $(\mathrm{Rz})$ of a surface were determined. These parameters were quantified using a profilometer (TR-100 Surface Roughness Tester).

Bioactivity of the composites was assessed by an in vitro simulated body fluid (SBF) test according to the method described in the work of Niemiel et al. ${ }^{28} \mathrm{In}$ brief, SBF was prepared by dissolving the following chemicals (POCh, Gliwice, Poland) in UHQ-water: $141 \mathrm{mM} \mathrm{NaCl}, 4 \mathrm{mM} \mathrm{KCl}, 0.5 \mathrm{mM} \mathrm{MgSO} 4,1 \mathrm{mM}$
$\mathrm{MgCl}_{2}, \quad 4.2 \mathrm{mM} \quad \mathrm{NaHCO}_{3}, \quad 2.5 \mathrm{mM} \quad \mathrm{CaCl}_{2}$, and $1.0 \mathrm{mM} \mathrm{KH} \mathrm{KHO}_{4}$. The resulting $\mathrm{SBF}$ was buffered to $\mathrm{pH} 7.28$ with Tris(hydroxymethyl aminomethane)/ $\mathrm{HCl}$. The sheets weighing $1 \mathrm{~g}$ were immersed in $100 \mathrm{~mL}$ of SBF solution and incubated at $37^{\circ} \mathrm{C}$ for 10 days. The SBF solution was exchanged every 3 days to ensure sufficient ion concentrations for mineral growth. Afterwards the samples were washed in UHQwater, air- and vacuum-dried to a constant weight.

Microstructure and chemical composition of PLGA and composite sheets before and after soaking in SBF were examined by SEM/EDAX analysis (NanoSEM, FEI, USA, accelerating voltage 10 and $18 \mathrm{kV}$, magnifications $500 \times$ and $5,000 \times$ ). The EDAX spectra were averaged for the whole analyzed surface at the magnification of $5,000 \times$.

\section{Material Sterilization}

For cell culture, composite sheets (round samples matching the size of culture vessels) were sterilized by soaking in $70 \%$ ethanol for $30 \mathrm{~min}$, washed with phosphate buffered saline (PBS) and further sterilized by UV light for $15 \mathrm{~min}$. 3D scaffolds were sterilized in $70 \%$ ethanol for $72 \mathrm{~h}$, washed in PBS and air-dried before cell seeding.

\section{Cell Cultures}

\section{Evaluation of $2 D$ Sheets}

Adult human bone marrow cells (BMC) were harvested from iliac crest of 10 adult patients (age 19-71, both genders) under Institutional Review Boardapproved protocol (KBET/17/L/2007). The mononuclear fraction, which contains both mesenchymal and hematopoetic cells, was isolated as described previously. ${ }^{30}$ Cells were either expanded in primary culture to select for MSC or they were directly seeded on the sheets (BMC mononuclear fraction). For selection of MSC, primary BMC were cultured in tissue culture flasks using alpha-MEM supplemented with $10 \%$ pre-selected MSC-qualified fetal bovine serum (MSC-FBS) and 1\% antibiotics (Penicillin/Streptomycin; Invitrogen). Medium was changed twice weekly until a confluent cell monolayer was developed. Cells were then detached from culture flasks using $0.25 \%$ Trypsin-EDTA (Invitrogen) and seeded onto the composite sheets or further expanded. To induce alkaline phosphatase (ALP) activity, the early marker of osteogenesis, MSC were seeded on composite sheets (round samples of $15 \mathrm{~mm}$ in diameter) at a density of $10^{4}$ cells $/ \mathrm{cm}^{2}$ and cultured in either alpha-MEM/MSC-FBS/antibiotics or supplemented with $100 \mu \mathrm{g} / \mathrm{mL}$ ascorbate-2-phosphate (ascorbate; Sigma) and $100 \mathrm{ng} / \mathrm{mL}$ recombinant human BMP-2 (BMP-2; R\&D Systems). Gene expression of 
osteogenic markers was analyzed in parallel cultures established on composite sheets of higher surface area (round samples of $28 \mathrm{~mm}$ in diameter) and treated with ascorbate and BMP-2. For calcium deposition, cultures were supplemented with $100 \mu \mathrm{g} / \mathrm{mL}$ ascorbate, $10 \mathrm{mM}$ $\beta$-glycerophosphate (Sigma), $100 \mathrm{ng} / \mathrm{mL} \mathrm{BMP-2}$ or $10^{-7} \mathrm{M}$ dexamethasone (Sigma). Analyzes were performed after 1 week (MTS, ALP, gene expression studies) or 3 weeks (calcification of extracellular matrix) of culture. Osteoclast formation was induced using BMC mononuclear fraction. After fractionation of whole bone marrow sample over Ficol gradient a mononuclear fraction of BMC was isolated and washed in sterile PBS to get rid of Ficol residues. ${ }^{30}$ Mononuclear cells were seeded on PLGA and composite sheets (round samples of $28 \mathrm{~mm}$ in diameter) at a density of $4.7 \times 10^{6} \mathrm{cell} /$ well $/ 6$-well plates in alpha-MEM/MSCFBS/antibiotics and supplemented with $100 \mathrm{ng} / \mathrm{mL}$ human recombinant macrophage colony stimulating factor (M-CSF, Peprotech). After 3 days of culture, medium, and floating cells were collected, transferred to corresponding standard tissue culture 6-well plates and further cultured in standard alpha-MEM/MSC-FBS/ antibiotics for a total of 23 culture days. Medium was changed every 3 days starting from culture day 8 .

\section{Evaluation of 3D Scaffolds}

MG-63 cells (human bone osteosarcoma-derived cells; Lonza USA) were expanded using DMEM High Glucose (Biosera, UK) supplemented with 10\% FBS (PAA), $1 \%$ antibiotics, and $0.25 \%$ fungizone (Sigma). For experiments with 3D composites and control PLGA 3D scaffolds MG-63 cells were suspended at a density of $2 \times 10^{5}$ cells $/ 150 \mu \mathrm{L}$ of PBS containing $1.75 \mathrm{mg} / \mathrm{mL}$ of fibrinogen (Sigma). To induce clot formation, cell suspension was supplemented with thrombin (1 unit $/ \mathrm{mL})$. Each 3D scaffold $(12 \mathrm{~mm}$ in diameter, $2 \mathrm{~mm}$ thickness) was placed in a separate well of 6-well plate and held by stainless steel ring to facilitate cell loading. Aliquots of $150 \mu \mathrm{L}$ cell suspensions were loaded into the scaffolds and incubated for $40 \mathrm{~min}$ at $37{ }^{\circ} \mathrm{C}$ in a humidified, $5 \% \mathrm{CO}_{2}$ atmosphere, followed by addition of standard DMEM/FBS/antibiotics. After $24 \mathrm{~h}$ of initial culture, the steel ring was removed and medium was supplemented with $50 \mu \mathrm{g} /$ $\mathrm{mL}$ ascorbate-2-phosphate, $10^{-7} \mathrm{M}$ dexamethasone, and $5 \mathrm{mM} \beta$-glycerophosphate (Sigma). Media and supplements were changed every $2-3$ days and analyzes done after 2 weeks of culture.

\section{D Culture Analyzes}

Seven-day osteogenic cultures were analyzed for cell metabolic activity using CellTiter96AQueous One
Solution Cell Proliferation Assay (MTS, Promega), a tetrazolium salt assay. Cell numbers of human MSC or MG-63 cells were estimated based on standard curves established with cells cultured at different densities and $A_{490 \mathrm{~nm}}$ MTS values that were measured at appropriate time intervals. The linear regressions between cell numbers and $A_{490 \mathrm{~nm}}$ MTS values were evaluated and the linear regression equations from the data fitting were used to determine the experimental cell numbers. ALP activity was assayed as described previously, ${ }^{37}$ and the results were normalized to live cell number to obtain specific ALP activity/cell values. We have previously determined that, using our hMSC culture regimens, ALP peaks at day 7 and reaches plateau by day $10,9,10,29,30$ and day 7 culture time point was previously used to analyze cellular ALP activity on different bioglass surfaces. ${ }^{17}$ Analyzes of gene expression levels in osteogenic cultures were performed after 7day cultures on selected composite sheets and PLGA, and compared to gene expression levels in cells cultured on standard tissue culture plastic (TCP). Briefly: $2 \mu \mathrm{g}$ of total RNA from each culture $\left(\right.$ NucleoSpin ${ }^{\circledR}$ RNA II, MACHEREY-NAGEL) were reverse-transcribed to cDNA (SuperScript III First Strand Synthesis System, Invitrogen) and used for the analyzes of gene expression levels in StepOnePlus Real-Time PCR apparatus (Applied Biosystems). Samples of cDNA were diluted $10 \times$ and $2-\mu \mathrm{L}$ aliquots of diluted cDNA were used for PCR reactions. Each reaction mixture (15 $\mu \mathrm{L}$ total volume) contained cDNA, gene-specific primers, SYBR ${ }^{\circledR}$ Green I, AmpliTaq Gold ${ }^{\circledR}$ DNA Polymerase and the reaction buffer as recommended by the manufacturer (SYBR ${ }^{\circledR}$ Green PCR Master Mix, Applied Biosystems). The following primers were used for the PCR analyzes: TATA (house keeping gene) forward 5'-GGAGCTGTGATGTGAAGTTTACTA-3', reverse 5'-CCAGGAAATAACTCTGGCTCATAA C-3'; BMP-2 forward 5'-TGCTAGTAACTTTTGGC ATGATG-3'; reverse 5'-GCGTTTCCGCTGTTTGT GTT-3'; MSX-2 forward 5'-GCACCCTGAGGAAA CACAAG-3', reverse 5'-GGTGGTCGCTTCGGTA AA-3'; osterix (OSX) forward 5'-ACTCACACCCGG GAGAAGAA- $3^{\prime}$, reverse 5'-GGTGGTCGCTTCGG GTAAA-3'; osteopontin (OPN) forward 5'-TGGAA AGCGAGGAGTTGAATG-3', reverse 5'-CATCCA GCTGACTCGTTTCATAA-3', bone sialoprotein (BSP) forward: 5'-AATGAAAACGAAGAAAGCG AAG-3', reverse 5'-ATCATAGCCATCGTAGCCTT GT-3', osteocalcin (OC) forward 5'-AAGAGACCCA GGCGCTACCT-3', reverse 5'-AACTCGTCACAGT CCGGATTG-3'. The PCR reactions were performed for 40 cycles with denaturation step at $95{ }^{\circ} \mathrm{C}$ for $30 \mathrm{~s}$, annealing at $60{ }^{\circ} \mathrm{C}$ for $1 \mathrm{~min}$, and elongation at $72{ }^{\circ} \mathrm{C}$ for $30 \mathrm{~s}$. Relative quantification (ddCT method) was used to analyze the results. Osteoclast formation was 
monitored throughout the culture period using an inverted contrast-phase microscope (Axiovert 40, Carl Zeiss). At the end of culture, pre-osteoclasts and osteoclasts were stained for tartrate-resistance acid phosphatase, as previously described. ${ }^{20}$

\section{$3 D$ Culture Analyzes}

3D cultures were analyzed at day 14 for live cell number by MTS, collagen production and calcification of extracellular matrix. After MTS assay the scaffolds were washed with PBS, fixed with $0.5 \mathrm{~mL}$ of $8 \%$ formalin solution and cut in halves to facilitate the staining and destaining procedures. For collagen detection, $1 \mathrm{~mL}$ of Sirus Red (Sigma) was added per scaffold and staining was performed for $18 \mathrm{~h}$ at room temperature with gentle rocking. Afterwards, the stain was removed, scaffolds extensively washed with deionized water and destained for few minutes using $0.5 \mathrm{~mL}$ of a solution containing equal volumes of $0.2 \mathrm{M}$ sodium hydroxide and methanol. For calcification of extracellular matrix, $1 \mathrm{~mL}$ of $0.1 \%$ Alizarin Red $\mathrm{S}$ water solution was added per scaffold and staining was performed at room temperature for $40 \mathrm{~min}$ with vigorous shaking. Destaining was performed for 10 min using $0.5 \mathrm{~mL}$ of $5 \%$ perchloric acid water solution per scaffold and gentle rocking. Recovered stains were then transferred to a clear 96-well plate in $200-\mu \mathrm{L}$ aliquots and the absorbance was read at $490 \mathrm{~nm}$ using a plate reader. Collagen and calcification results were normalized to live cell number to obtain specific collagen/cell and mineral/cell values. For the analyzes of cell distribution with the confocal microscope, the scaffolds were fixed in $8 \%$ formalin solution at room temperature for $20 \mathrm{~min}$. Then the scaffolds were washed three times with PBS. Actin cytoskeleton of the cells was visualized with phalloidinTRITC solution (Molecular Probes, Invitrogen) in PBS (1:2000 dilution of the original stock). $1 \mathrm{~mL}$ of staining solution was added to each scaffold for $40 \mathrm{~min}$. Then the scaffolds were washed three times with PBS followed by nuclei staining with DAPI in PBS (1 mL DAPI/scaffold; 1:1000 dilution of original DAPI stock) for $30 \mathrm{~min}$. The confocal images were taken as 12-bit z-stack with LSM 510 Meta microscope using $40 \times$ magnification of achroplan objective.

\section{Statistical Analysis}

Multi-way ANOVA was used for statistical analyzes of mechanical properties and contact angle values. Biological evaluations were done with at least three separate cultures and data from each culture were usually collected in triplicates. Because the number of biological samples from each studied group was less than 10 , data were analyzed by nonparametric Kruskal-Wallis test, followed by Tukey post hoc test: $p<0.05$ was considered significant.

\section{RESULTS}

\section{Mechanical Properties and Water Contact Angle}

The mechanical properties of PLGA and PLGA/ S-BG composites are given in Figs. 1a-1c. Tensile strength $(\mathrm{Rm})$ was comparable for pure PLGA and composites containing either $21 \% \mathrm{~S} 2$ or $21 \% \mathrm{~A} 2 \mathrm{~S}-\mathrm{BG}$. Low S-BG contents $(12 \%)$ in the composites enhanced, and high $(33 \%)$ reduced tensile strength (Fig. 1a). All composites, except for PLGA/A2-33 had significantly higher Young's modulus (Fig. 1b) and all exhibited significantly lower elongation at break (Fig. 1c) compared to pure PLGA (Figs. 1b, 1c). Contact angle values for PLGA/A2 composites were significantly lower than for PLGA/S2 composites (Fig. 1d). Contact angle values for the latter were comparable to pure PLGA. Surface roughness parameters, i.e., the arithmetical mean roughness (Ra) and ten-point mean roughness depth $(\mathrm{Rz})$ (Table 1) increased with increased S-BG content in the composites. Ra values for composites containing $33 \%$ of either S-BG were comparable to values obtained for pure PLGA. In contrast, $\mathrm{Rz}$ values for composites containing either S-BG were approximately $5-13$ fold higher compared to $\mathrm{Rz}$ of pure PLGA, depending on S-BG content.

\section{Degradation Rate}

Degradation rates of the samples were evaluated based on $\mathrm{pH}$ and conductivity measurements of the incubation medium (Fig. 2) and compared to degradation rates of pure PLGA and pure bioactive glasses $\mathrm{S} 2$ or A2. Materials in the form of sheets were soaked in UHQ-water for 3 months. Pure PLGA did not influence $\mathrm{pH}$ and conductivity of the incubation medium up to the tenth week of incubation; this was followed by a rapid decrease of $\mathrm{pH}$ and increase of conductivity of the incubation medium. In contrast, the $\mathrm{pH}$ of the composites' incubation media stabilized at neutral level by second week and remained unchanged until the end of experiments (Figs. 2a, 2c). Notably, PLGA/A2 composites containing either $21 \%$ or $33 \%$ A2 alkalized the incubation media during initial 2-week incubation period (Fig. 2c) and the conductivities of these incubation media were markedly increased compared to other materials studied (Fig. 2d). For PLGA/S2 bioactive glass, conductivities of their incubation media increased slightly within the 

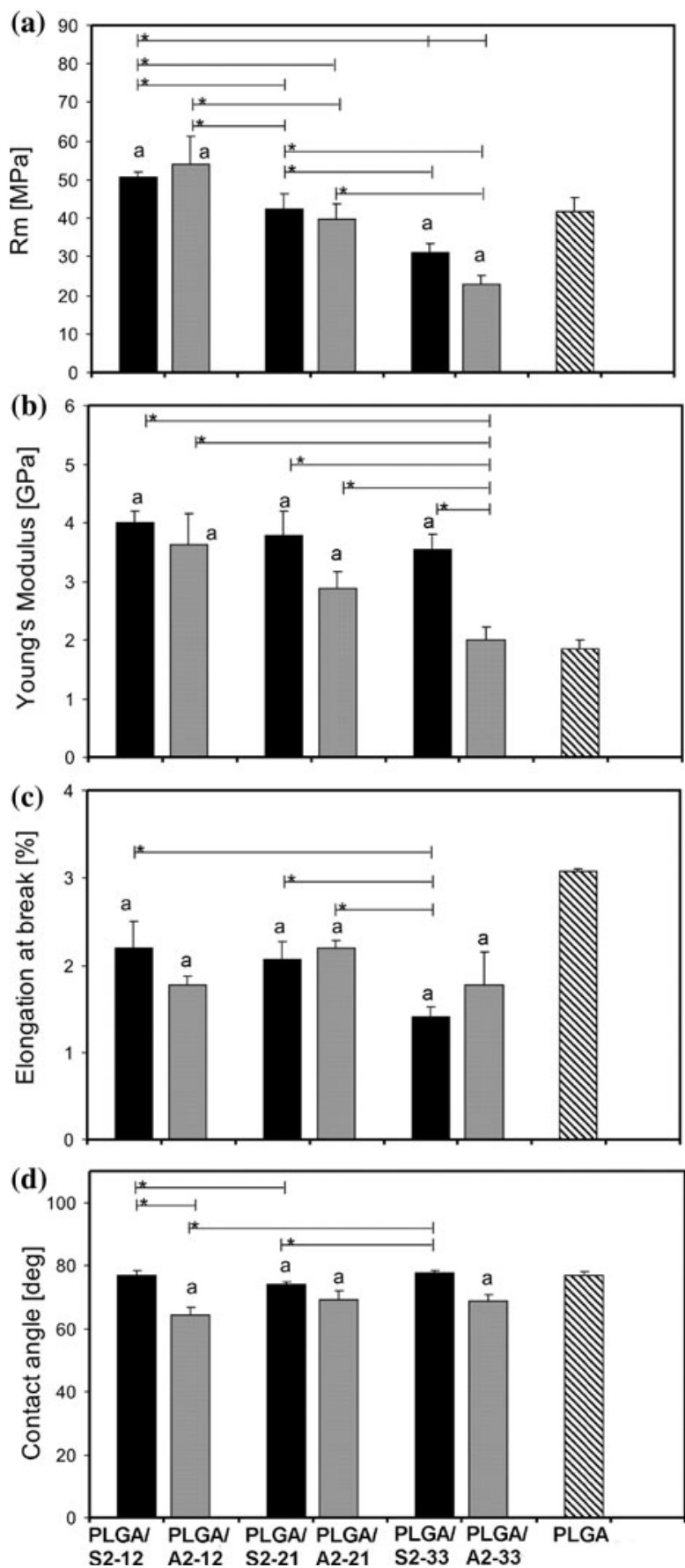

FIGURE 1. Tensile strength Rm (a), Young's modulus (b), elongation at break $\varepsilon$ (c), and contact angle values (d) of PLGA and PLGA/S-BG composites. Results are expressed as mean \pm S.E. Statistically significant differences $(p<0.05)$ from PLGA are indicated by letter code a. Statistically significant differences between other groups are indicated by connectors and asterisk.

first week, and remained unchanged till the end of the experiment (Fig. 2b). Notably, the conductivity values obtained for PLGA/S2 incubation media did not reach the values comparable to those obtained for PLGA/A2 composites throughout the entire incubation period.

Figures $3 \mathrm{a}, 3 \mathrm{~b}$ show that bioactive glass particles were evenly distributed on the surface of both PLGA/ S2-21 and PLGA/A2-21 composites. After 3-month incubation in UHQ-water the preferential erosion of the polymer at the interface PLGA base/bioglass particles was visible (Figs. 3c, 3d). As a result some of the bioglass particles were exposed and were able to release ions affecting $\mathrm{pH}$ and conductivity of incubation medium (Fig. 2).

\section{Evaluation of Bioactivity}

The formation of an apatite-like layer on the material surface as a result of soaking in SBF is a commonly used method to determine bioactive properties of materials. The results of SEM and EDAX analyzes for representative samples are shown in Figs. $4 \mathrm{a}-4 \mathrm{f}$. We did not observe any significant changes in surface morphology or chemical composition of pure PLGA sheets after soaking in SBF (Figs. 4a, 4b). The surfaces of PLGA-bioactive glass composites were smooth with uniformly distributed glass particles before the incubation in SBF (Figs. 4c, $4 \mathrm{e})$. Oxygen and carbon originating from PLGA, and small amounts of calcium and silicon originating from bioactive glass were detected by EDAX (Figs. 4c, 4e, insets). After incubation in SBF, PLGA/S2 bioactive glass composites displayed limited surface changes, though mineral deposits containing calcium and phosphorus were formed as detected by EDAX (Fig. 4d). On the contrary, distinct changes in surface morphology were observed for the PLGA/A2 bioactive glass composites (Fig. 4f). The latter was covered with spherical calcium phosphate nodules of cauliflower-like morphology, typical of hydroxyapatite precipitated from SBF. ${ }^{12,18,36}$ FTIR-ATR analysis, performed according to the method described previously, ${ }^{12}$ confirmed that low-crystalline hydroxyapatite was created on the surface of PLGA/A2-21, but not on the surface of PLGA/S2-21 (data not shown). These results indicate that incorporation of bioactive glass particles into PLGA enhanced formation of apatite-like bioactive layer on the composite surfaces, though this was dependent on the chemical composition of incorporated bioactive glass. Addition of bioactive glass of high $\mathrm{CaO}$ concentration (A2) resulted in faster apatite-like layer formation. It seems this bioactive glass is a more effective source of $\mathrm{Ca}$ than S2 bioactive glass. Consequently, supersaturation of SBF solution in relation to apatite is faster in the presence of PLGA/A2 S-BG composites than PLGA/S2 S-BG containing ones. 
TABLE 1. Surface roughness parameters (Ra, Rz) of PLGA and PLGA/S-BG composites (mean \pm S.D.).

\begin{tabular}{lcccrrrr}
\hline & PLGA & PLGA/S2-12 & PLGA/S2-21 & PLGA/S2-33 & PLGA/A2-12 & PLGA/A2-21 & PLGA/A2-33 \\
\hline Ra $(\mu \mathrm{m})$ & $1.54 \pm 0.28$ & $0.59 \pm 0.08$ & $0.8 \pm 0.1$ & $1.5 \pm 1.5$ & $0.75 \pm 0.07$ & $1.6 \pm 0.1$ & $1.7 \pm 0.1$ \\
$\mathrm{Rz}(\mu \mathrm{m})$ & $1.15 \pm 0.81$ & $5.30 \pm 0.68$ & $7.4 \pm 1.0$ & $13.7 \pm 1.6$ & $6.7 \pm 1.1$ & $11.8 \pm 1.4$ & $12.7 \pm 1.1$ \\
\hline
\end{tabular}
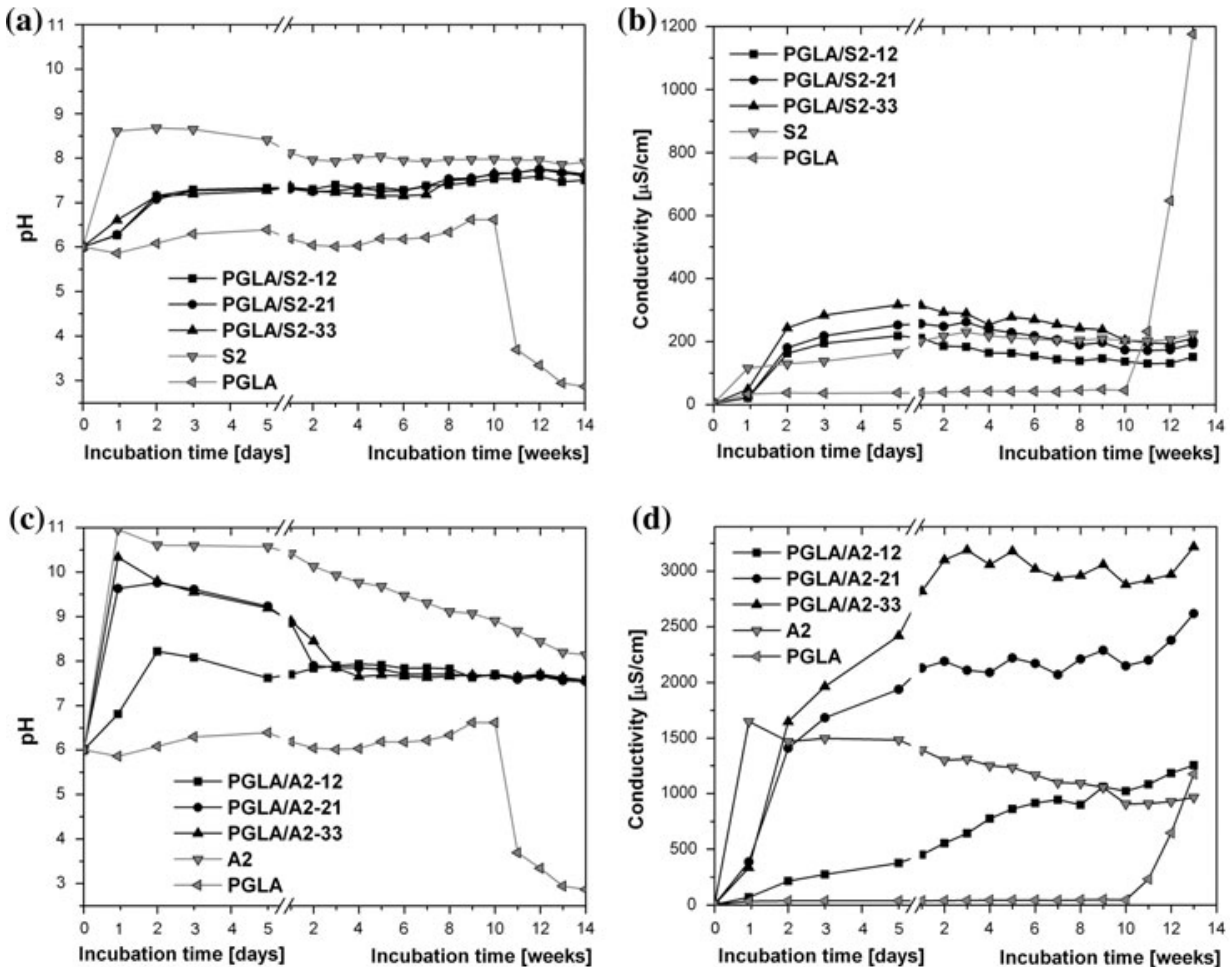

FIGURE 2. UHQ-water $\mathrm{pH}(\mathrm{a}, \mathrm{c})$ and conductivity $(\mathrm{b}, \mathrm{d})$ changes during 3-month incubation of PLGA/S-BG composite samples and starting compounds (PLGA and bioactive glass S2 or A2).

\section{Interaction of Cells with Composite Materials}

\section{Evaluation of $2 D$ Cultures}

Cell numbers were estimated based on MTS standard curve for human MSC cultures that were seeded at different densities and culture media were assayed for $A_{490 \mathrm{~nm}}$ changes at appropriate time intervals. Cell numbers of human MSC cultured for 7 days on PLGA/S2-12 and PLGA/S2-21 composite sheets in standard medium were comparable to cultures on pure PLGA and significantly higher than on TCP (Fig. 5a). The number of cells grown on other composite sheets was not different from those on TCP.

Human MSC cell numbers decreased with increased bioactive glass content as a result of culturing hMSC on composite sheets in osteogenic medium containing bone morphogenetic protein 2 (BMP-2) (Fig. 5b). We have previously indicated BMP-2 to be a week inducer of osteogenesis in human compared to rodent MSC cultures ${ }^{29}$ and also a poor osteogenic inducer in standard serum-containing human MSC cultures compared to dexamethasone. ${ }^{9,10}$ Thus, it was of interest to test the BMP response of human MSC on bioactive composite sheets. We determined that specific ALP activity (i.e., ALP/cell) significantly increased for PLGA/A2 composites compared to TCP and the increases were proportional to the bioactive glass content (Fig. 5c). Pure PLGA sheets provided similar results. Specific ALP activity for PLGA/S2-33 sheets was higher than PLGA/S2-12 and PLGA/S2-21, but the results were not statistically significant and none was significantly different from the specific ALP activity of cells grown on TCP. Real-time PCR analyzes of gene expression levels that are characteristic for cells undergoing osteogenic differentiation were performed after 7-day hMSC culture on PLGA and composite sheets containing either $21 \% \mathrm{~S} 2$ or $21 \% \mathrm{~A} 2$ $\mathrm{S}-\mathrm{BG}$, and results referred to gene expression levels for cells cultured on TCP (Fig. 6). The selection of composites for gene expression studies was based on 

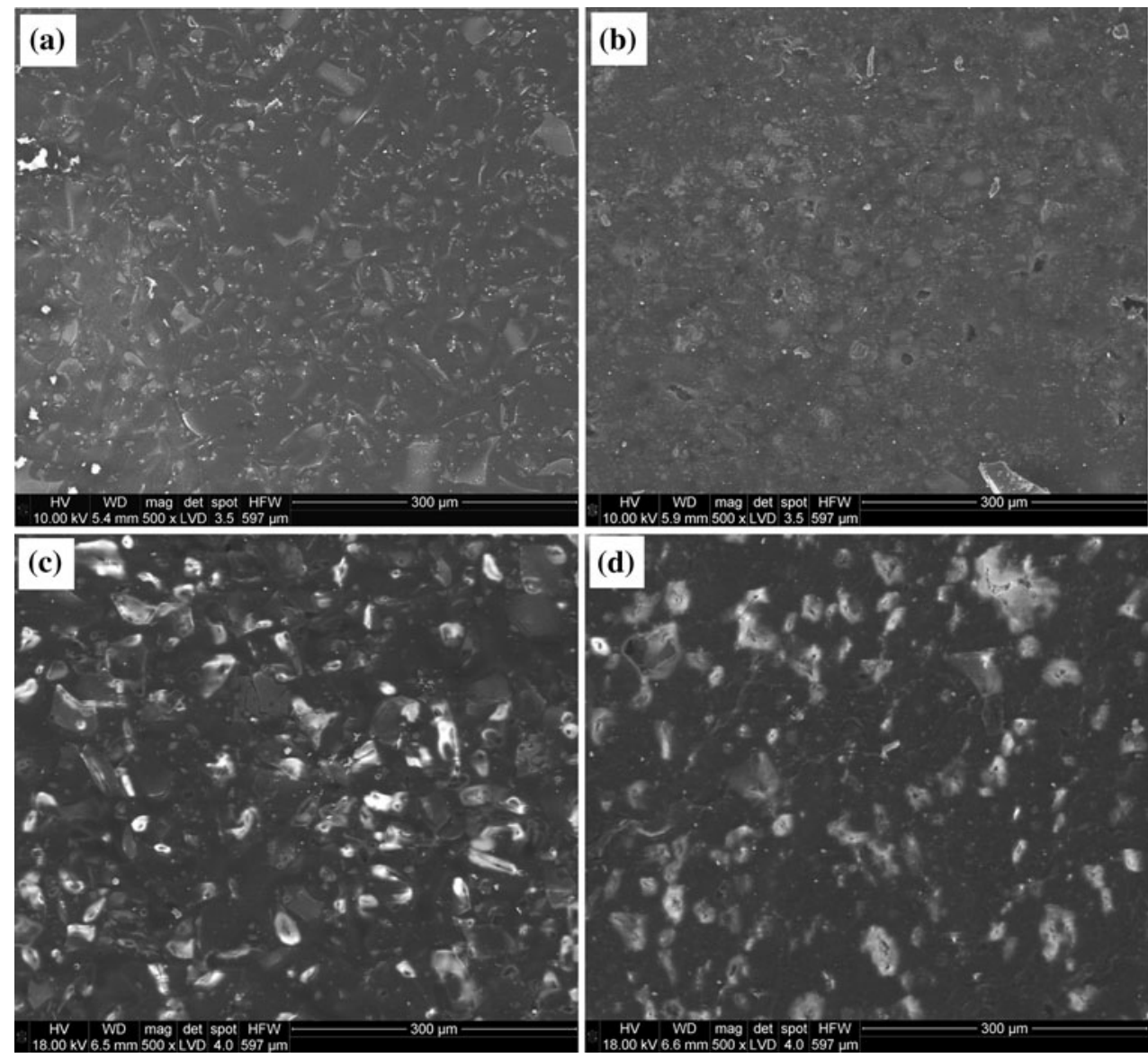

FIGURE 3. SEM pictures of PLGA/S2-21 before (a) and after incubation in UHQ-water for 3 months (c), PLGA/A2-21 before (b) and after incubation in UHQ-water for 3 months (d); original magnification $\times 500$.

moderate mechanical and biological properties of these sheets. The analyzed transcripts included $B M P-2$ mRNA, since BMP-2 can regulate its own expression, and $M S X-2$ and OSTERIX that are transcription factors expressed early during osteogenesis and regulated by BMP- $2 .^{21}$ In addition, we analyzed OSTEOPONTIN, BONE SIALOPROTEIN and OSTEOCALCIN that are synthesized by osteoblasts and deposited in bone matrix. The results showed comparable expression levels for most selected genes on all studied surfaces (Figs. 6a-6f) suggesting that osteogenic differentiation of hMSC by day 7 cultures was not significantly affected by the composite surface properties and/or their dissolution products. It should be noted, however, that hMSC grown on composite sheets expressed significantly higher levels of $B M P-2$ (PLGA/A2-21 vs. PLGA/S2-21; PLGA/A2-21 vs. TCP; Fig. 6a) and OSTEOPONTIN (OPN) mRNA (PLGA/S2-21 and PLGA/A2-21 vs. TCP; PLGA/S221 vs. PLGA/A2-21; Fig. 5d) and significantly lower levels of $M S X-2$ mRNA (PLGA/A2-21 vs. TCP; Fig. 5b).
Human MSC grown for 3 weeks on TCP in BMP-2 containing osteogenic conditions stained mildly for Alizarin Red S, but staining was clearly visible for cells for which osteogenesis was induced by dexamethasone (data not shown). When hMSC were grown on PLGA/S-BG composites, strong Alizarin Red S staining was apparent on all PLGA/S2 and PLGA/A2-12 composite sheets. Corresponding sheets incubated in cell-free conditions remained unstained. Thus, these materials enhanced cell-mediated calcification of extracellular matrix, and this was the case for either dexamethasone or BMP-2 treated cells (Fig. 7). For PLGA/A2-21 and PLGA/A2-33 the Alizarin red staining intensity was very high without cells, thus it was difficult to distinguish between material-induced and cell-induced calcification. Pure PLGA sheets remained unstained with or without cells and regardless of culture treatments.

When primary BMC were pre-treated with M-CSF for 3 days on PLGA-bioactive glass sheets, followed by 3 -week culture of floaters on TCP in standard medium, the morphology of cells that came into 

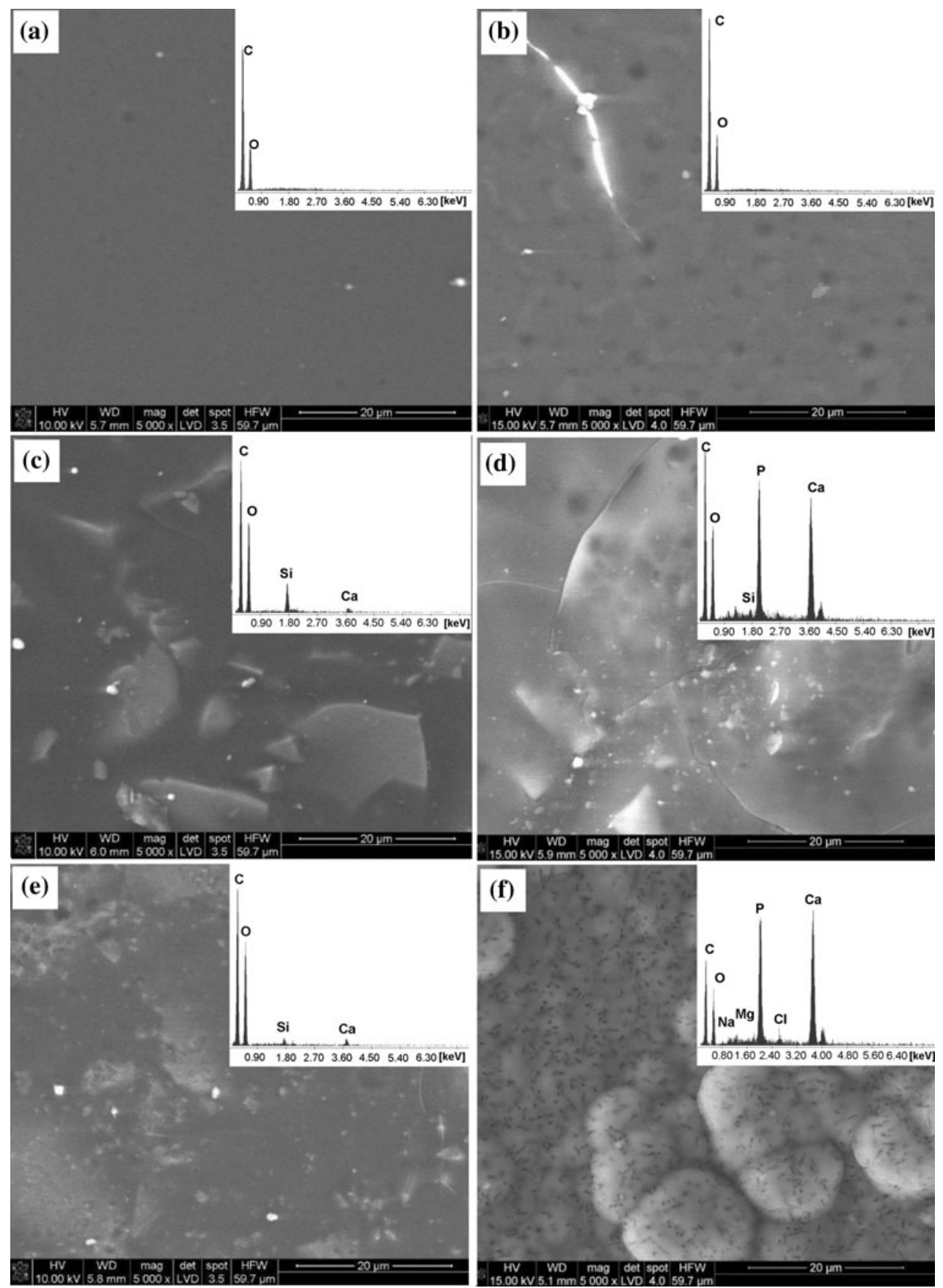

FIGURE 4. SEM pictures and EDAX spectra (insets) of: PLGA surface before (a) and after 10-day incubation in SBF (b), PLGA/S221 before (c) and after 10-day incubation in SBF (d), PLGA/A2-21 before (e) and after 10-day incubation in SBF (f); original magnification $\times 5,000$.

contact with PLGA/A2-21 sheets was distinct from these pre-cultured on PLGA/S2-21 and pure PLGA sheets. Round, TRAP-positive and multinucleated cells could be observed in cultures established from floating cells aspirated from PLGA/A2-21 (Figs. 8c, 8d), whereas cells transferred from PLGA/S2-21 and pure PLGA sheets developed into fibroblast-like cells negative for TRAP (Figs. 8a, 8b).

\section{Evaluation of $3 D$ Cultures}

MG-63 cells loaded into 3D PLGA, PLGA/S2-21, and PLGA/A2-21 attached to the sides of the scaffold pores and remained viable after 2 weeks of culture, as determined by phalloidin/DAPI staining (Fig. 9a, confocal images). Cell numbers were comparable in all studied scaffolds as determined by MTS assay 

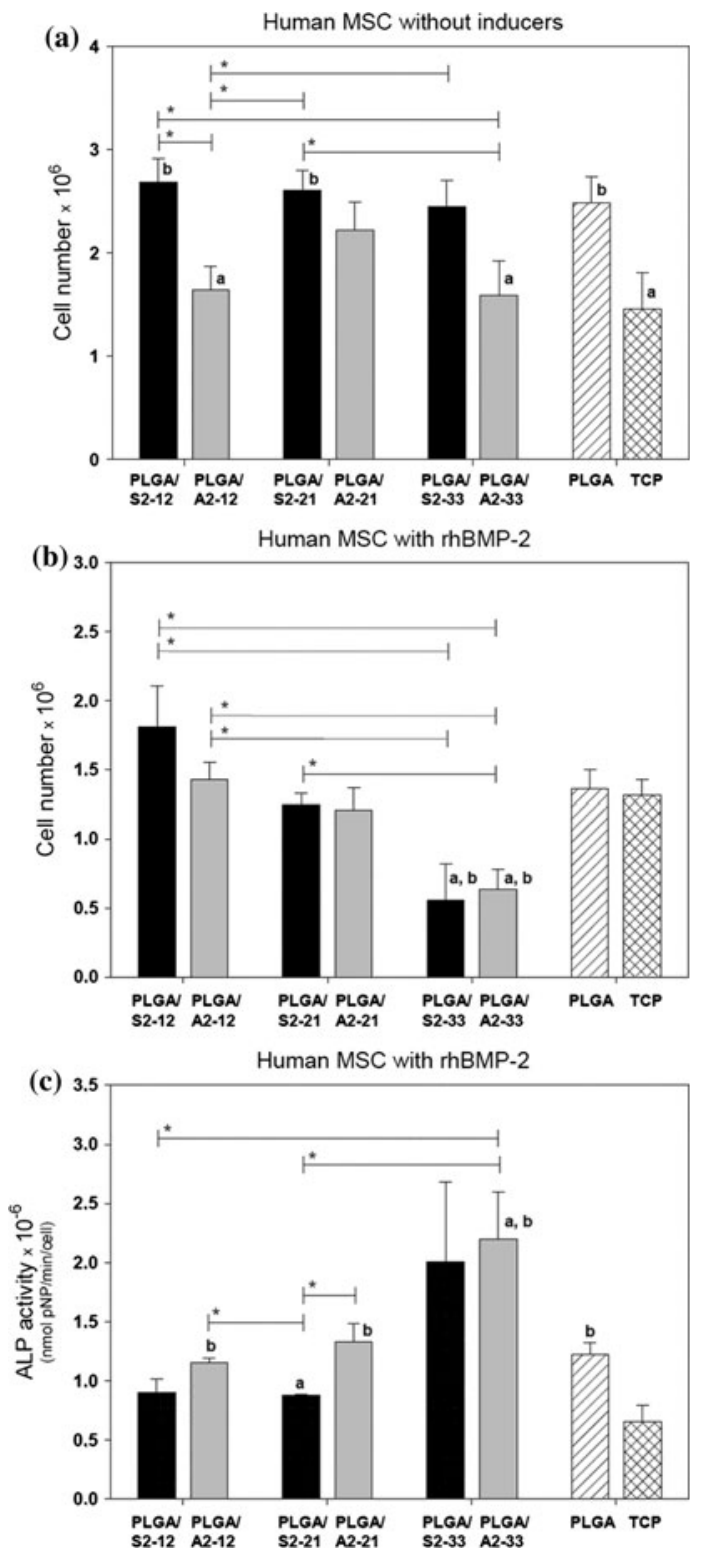

FIGURE 5. Growth and differentiation of human MSC after 7-day culture on PLGA/S-BG composites, pure PLGA and tissue culture plastic (TCP). Cell number after culture in standard conditions without osteogenic inducers (a) and after stimulation with rhBMP-2 (b). Alkaline phosphatase (ALP) activity of cells after stimulation with rhBMP-2 (c). Results are expressed as mean \pm S.E. Statistically significant differences $(p<0.05)$ from a PLGA and b TCP are indicated by letter code, respectively. Statistically significant differences between other groups are indicated by connectors and asterisk. Cell numbers were significantly higher on composite sheets containing low and mid w/v\% of S2 S-BG compared to TCP when cultured without inducers, and significantly lower on composite sheets containing low and high w/v\% of A2 S-BG compared to PLGA (a). When stimulated with rhBMP-2, cell numbers on composites containing high $w / v \%$ S-BG were significantly lower compared to either PLGA or TCP (b). Cells cultured on PLGA/A2-33 and stimulated with rhBMP-2 displayed significantly higher ALP activity levels compared to PLGA and TCP (c). ALP activity levels of cells stimulated with rhBMP-2 were significantly higher on all studied A2 S-BG and PLGA/S2-33 compared to TCP (c). described in "Materials and Methods" section (Fig. 9b). In contrast, the production of collagen/cell (Fig. 9c) and calcium/cell (Fig. 9d) was significantly increased for cells cultured on composite scaffolds compared to pure PLGA.

\section{DISCUSSION}

We report here that the incorporation of either S2 or A2 sol-gel derived bioactive glass into PLGA results in composites of enhanced mechanical properties and tailored degradation rates, but biological activities of these composites depend both on the content and composition of the bioactive glass components.

Incorporation of either S2 or A2 S-BG into PLGA resulted in creation of stiffer materials compared to pure PLGA, as determined by increased Young's modulus and lowered elongation at break (Fig. 1). Tensile strength of the composites depended on the bioactive glass content and was significantly higher for composites containing $12 \%$ of either S-BG compared to pure PLGA. Notably, tensile strengths of these composites exceeded $50 \mathrm{MPa}$ (Fig. 1a), a value comparable to that of trabecular bone. ${ }^{7}$ The increase in tensile strength and Young's modulus of PLGA/S-BG composites suggests that S-BG particles act as a reinforcing phase within the polymer matrix. In addition SEM observations show that the S-BG particles are uniformly distributed within the PLGA base and do not form agglomerates (Figs. 3a, 3b). Thus, it is possible to obtain composites of mechanical properties similar to those of natural bone simply by adjusting bioactive glass content. Interestingly, similarly to recent work of Wu et al. ${ }^{41}$ increasing A2 S-BG content to $33 \%$ significantly decreased the tensile strength of the composites compared to pure PLGA; also the modulus of PLGA/A2-33 was significantly decreased compared to other composites (Fig. 1b). However, our SEM analyzes of composites containing 33\% of either S-BG indicated bioactive glass grains uniformly embedded in the polymer matrix with no microcracks (data not shown).

Both S2 and A2 containing composites displayed modified degradation rates compared to pure PLGA, S2 and A2 S-BG, and neutralized acidic degradation by-products of pure PLGA at later incubation stages, as determined by $\mathrm{pH}$ and conductivity of incubation solutions. Notably, higher contents of A2 S-BG in the composites increased both $\mathrm{pH}$ and conductivity of the environment; the latter was not observed for S2 S-BG (Fig. 2). PLGA degrades through chain scission of polyester bonds due to hydrolysis. This results in oligomers formation leading to final degradation products of glycolic and lactic acids. ${ }^{33}$ Thus, at tenth 
(a)

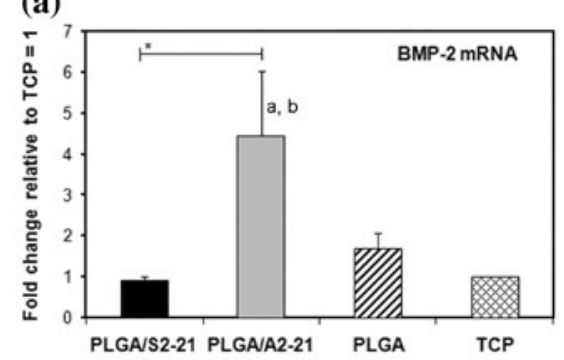

(d)

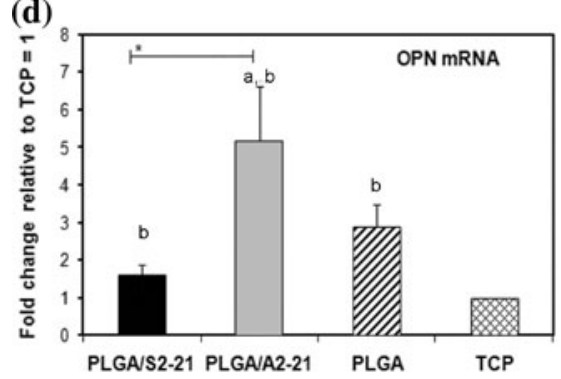

(b)

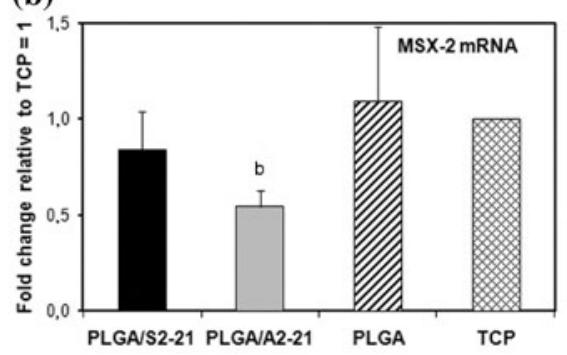

(e)

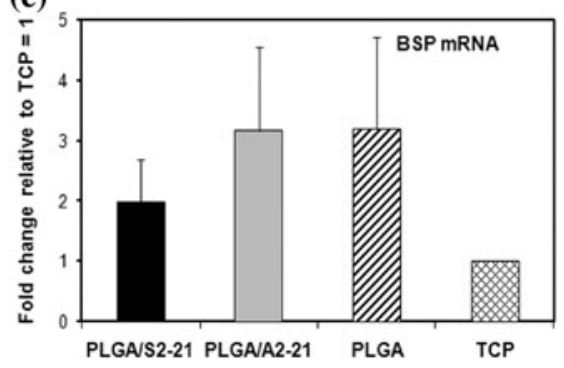

(c)

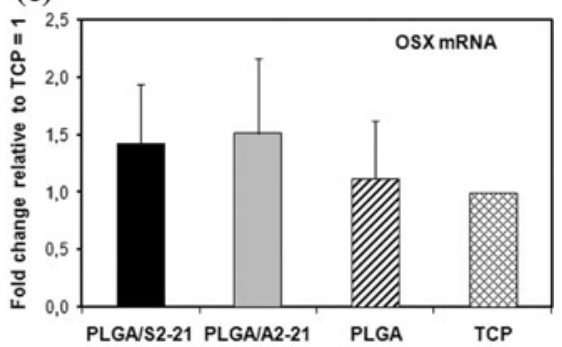

(f)

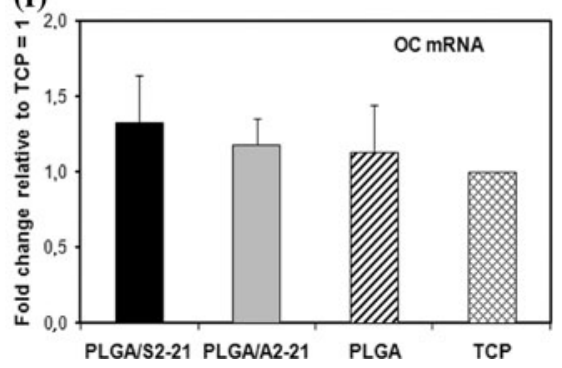

FIGURE 6. Real-time RT-PCR analyzes of gene expression levels in hMSC cultured for 7 days on PLGA, PLGA/S2-21, and PLGA/ A2-21. Cells were stimulated with ascorbate and BMP-2 and RNA harvested and analyzed as described in respective "Materials and Methods" sections. Fold changes relative to TCP $=1$ are presented (ddCT method). Results are expressed as mean \pm S.E. Statistically significant differences $(p<0.05)$ from a PLGA and b TCP are indicated by letter code, respectively. Statistically significant differences between other groups are indicated by connectors and asterisk. Human MSC cultured on PLGA/A2-21 sheets displayed significantly higher levels of BMP-2 and OPN mRNAs and significantly lower levels of MSX-2 mRNA.

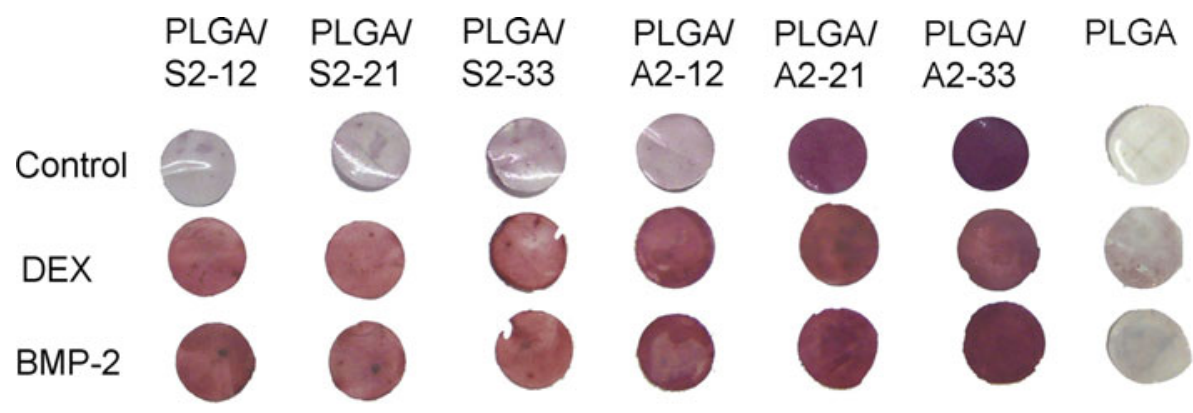

FIGURE 7. Comparison of Alizarin Red S staining intensities of PLGA/S-BG composite sheets and pure PLGA in cell-free conditions (control) and after osteogenic human MSC cultures induced with dexamethasone (DEX) and BMP-2. PLGA/S2 composite sheets enhanced cell-mediated calcification of ECM-these sheets stained strongly for Alizarin Red S only when subjected to osteogenic culture. Similar results were obtained for either Dex or BMP induced osteogenic cultures.

week in aqueous medium, the final PLGA degradation products decreased $\mathrm{pH}$ and increased conductivity of the incubation medium (Fig. 2). Immersion of S-BG in water provokes the increase of $\mathrm{pH}$ and conductivity due to release of calcium ions from the materials to the incubation medium, and protons uptake. Although PLGA/S2 composites did not provoke significant changes in $\mathrm{pH}$ and conductivity of the incubation medium, past the tenth week in water, their degradation rates remained constant in contrast to pure PLGA. This may be due to (i) lower degradation of the PLGA base in the $\mathrm{S} 2$ containing composites, or (ii) the acidic degradation products of PLGA reacting with alkaline degradation products of S2 bioactive glass.
The former can be ruled out based on reports indicating that the presence of ceramic particles or carbon fibers in PLGA composites speeds up degradation ${ }^{3,31}$ and forms a new interface that improves diffusion of water molecules into the bulk of the composites. Thus, it is plausible that the PLGA/S2 composites degrade faster than pure PLGA, however, due to the buffering capacity of S2 S-BG, $\mathrm{pH}$ and conductivity of the incubation medium do not change. Compared to PLGA/S2 composites, the PLGA/A2 composites displayed significantly higher $\mathrm{pH}$ and conductivity values and this positively correlated with the concentration of bioactive glass (Figs. 2c, 2d). Notably, after 3 weeks immersion of PLGA/A2 composites in UHQ-water, 

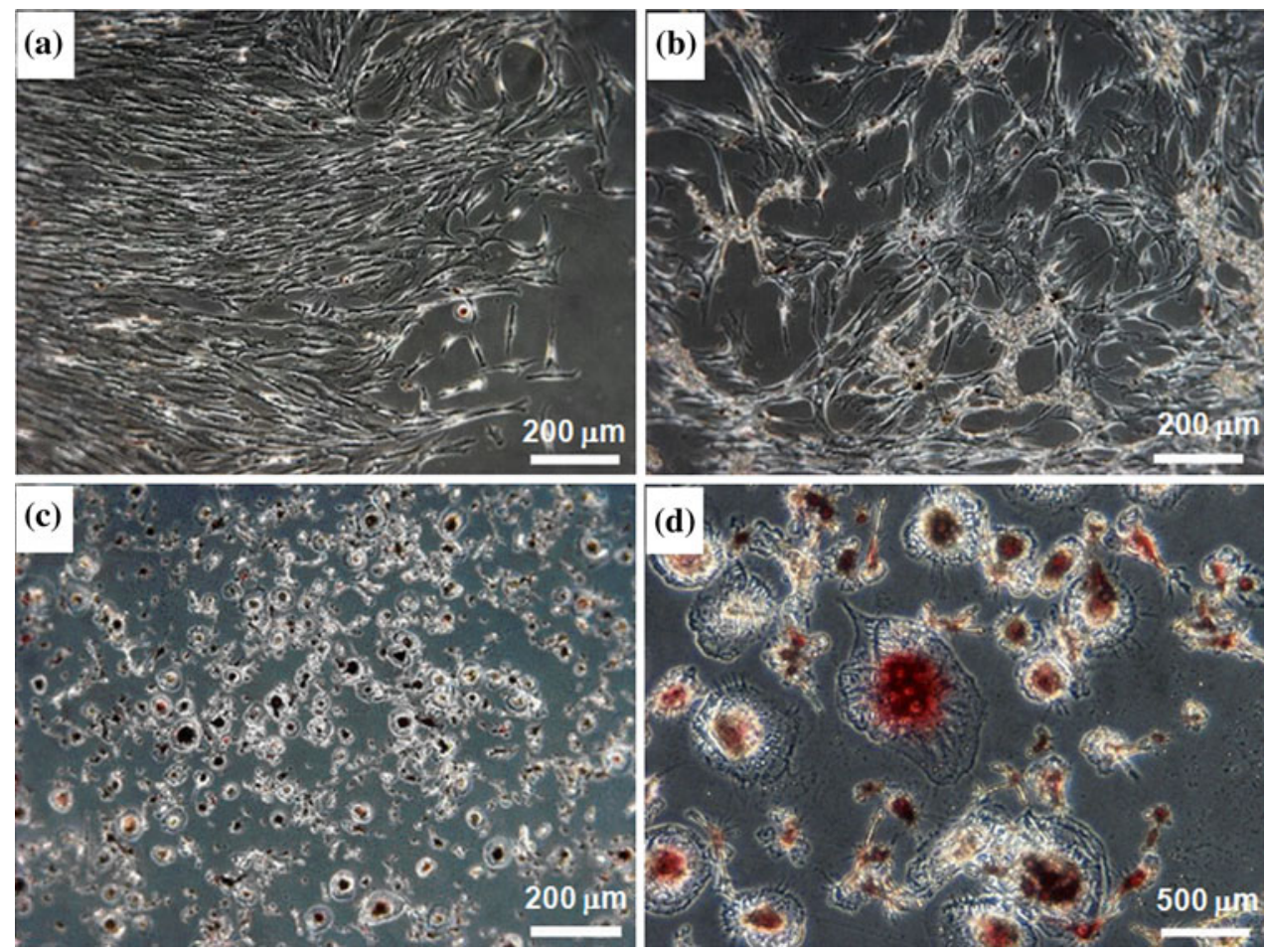

FIGURE 8. Tartrate-resistant acid phosphatase (TRAP) staining of bone marrow mononuclear cells pre-cultured for 3 days on pure PLGA and PLGA/S-BG composites in the presence of MCS-F, followed by 3-week culture in standard medium on tissue culture plastic. Cells pre-cultured on pure PLGA (a) and PLGA/S2-21 composites (b) displayed typical fibroblastic morphology and they were negative for TRAP. Positive TRAP staining and osteoclast-like morphology of cells was observed for cells pre-cultured on PLGA/A2-21 composites (c, d).

the $\mathrm{pH}$ stabilized at the level of 8 (Fig. 2c), whereas conductivity increased, especially for PLGA/A2-33 composites (Fig. 2d). This may be due to continuous release of calcium ions from A2 S-BG and local buffering effects of potential PLGA degradation products. Overall, both the chemical composition of the S-BG and the amount in the PLGA base contribute to the degradation rate of the resulting composites. Using the composites studied here, it is feasible to design a wide variety of biodegradable materials differing in degradation kinetics.

The cell numbers of bone marrow human MSC grown in non-differentiating conditions were significantly higher on PLGA/S2 composite sheets compared to PLGA/A2 (Fig. 5a). The latter was less hydrophobic (Fig. 1d) and this could have affected attachment and growth of osteoprogenitor cells. In contrast, when cells were grown in osteogenic BMP-containing medium, the number of cells was comparable on either S-BGcontaining composites and decreased with increased S-BG content (Fig. 5b). This corresponded to increased surface roughness parameters of the PLGA/S-BG composites with increased S-BG contents (Table 1). The effects of surface roughness and topography on bone cells have been well documented in the literature, ${ }^{14,22,40}$ who reported lower ALP activity of human osteoblast-like cells with increased bioactive glass content in PLAGA-55S5 BG composites. We observed significant increases of specific ALP/cell (Fig. 5c) in hMSC cultures grown on composites containing the highest proportion of A2 S-BG. It is plausible that PLGA/A2-33 composites slowed cell adhesion and/or proliferation rates, but stimulated osteogenic differentiation instead. Further analyzes of gene expression levels of hMSC grown on composite sheets of moderate properties (i.e., PLGA-21\% of either A2 or S2 BG) showed, in most cases, comparable expression of osteogenic markers that was not significantly different from cells cultured on either PLGA or TCP. This indicates that the studied surfaces support BMP-mediated osteogenic progression of hMSC at least to the same extent as polymer itself or TCP. However, hMSC grown on PLGA/A2-21 sheets had significantly higher $B M P-2$ mRNA expression levels compared to TCP suggesting they may enhance BMP-mediated signaling. In this respect, it is unclear why $M S X-2$ expression was decreased on PLGA/A2-21 sheets. Though, if these composites stimulated osteogenic differentiation of hMSC, they might as well induce expression of $M S X-2$ at earlier culture stages. Further studies are required to determine molecular mechanisms of BMP signaling on these composite sheets. 
(a)
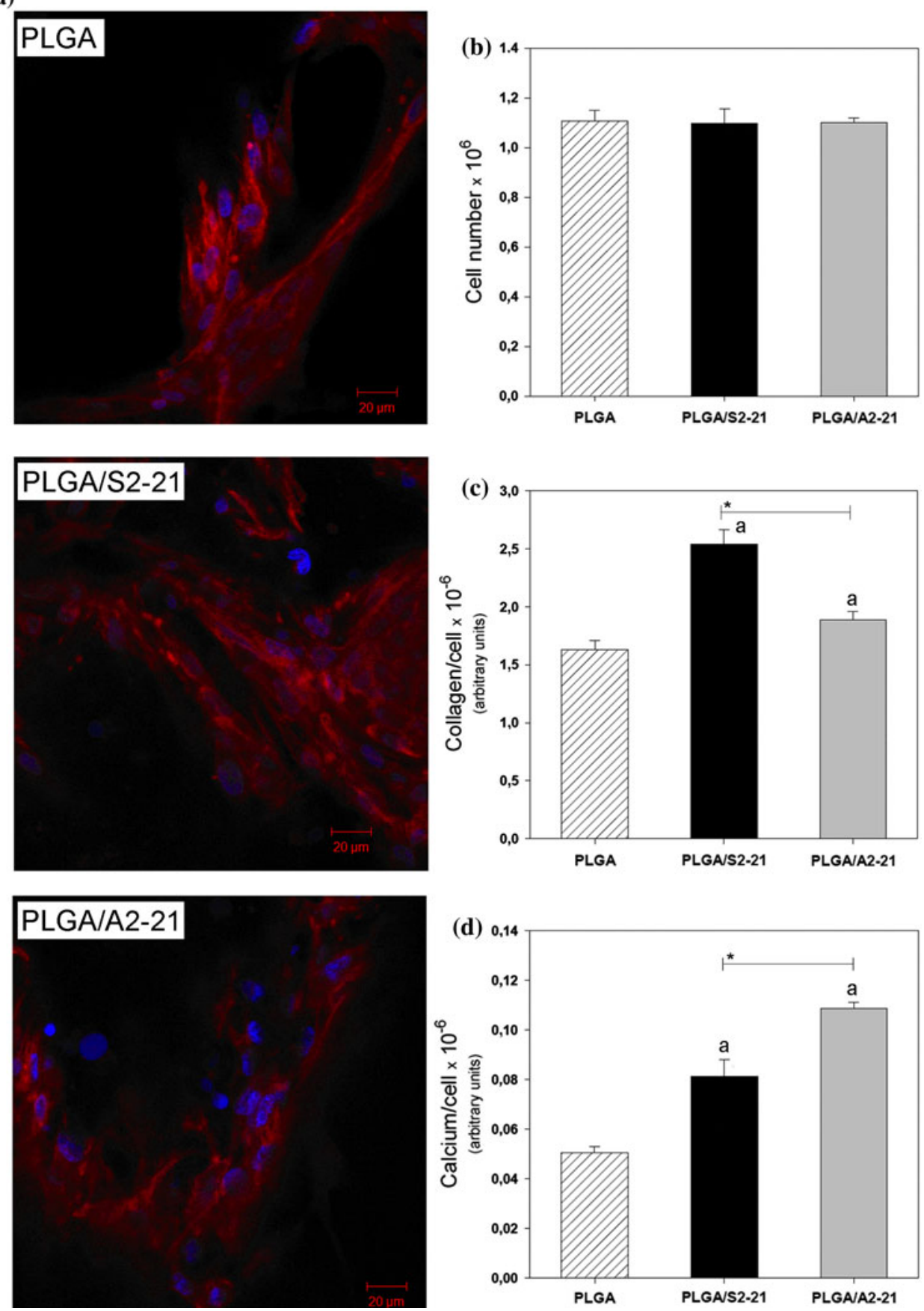

FIGURE 9. Phalloidin/DAPI staining (a) of MG-63 cells cultured in 3D PLGA, PLGA/S2-21, and PLGA/A2-21 scaffolds and stimulated with ascorbate, dexamethasone, and $\beta$-glycerophosphate for 2 weeks. Cells were also analyzed for cell number (b), collagen (c), and calcium (d) levels after 2-week culture. Results for $b-d$ are expressed as mean \pm S.E. Statistically significant differences $(p<0.05)$ from PLGA are indicated by letter code a. Statistically significant differences between other groups are indicated by connectors and asterisk. Comparable cell numbers were detected in all studied 3D scaffolds, but MG-63 cells cultured in PLGAS-BG 3D composites produced significantly higher levels of collagen and calcium compared to pure PLGA 3D scaffolds.

In the previous work of Karpov et al. ${ }^{17}$ pure A2 S-BG coatings induced moderate osteogenic effects in human bone marrow-derived MSC cultures, but acted as a potent inducer of osteoclast formation and survival. In this work hMSC grown on PLGA/A2-21 sheets expressed significantly higher levels of $O S T E$ OPONTIN mRNA as compared to PLGA/S2-21 or TCP. While elevated osteopontin expression is an early marker of osteoblast differentiation, it is also required for osteoclast formation. ${ }^{1,38}$ Furthermore, 
round, TRAP-positive multinucleated cells could be observed in cultures established from floating BMC aspirated after 3-day primary BMC culture from PLGA/A2-21 composite sheets, whereas cells transferred from PLGA/S2-21 and pure PLGA sheets developed into fibroblast-like cells negative for TRAP. This may be due to high surface reactivity of PLGA/ A2 composite sheets and their high bioactivity as determined by SBF studies (Fig. 4f) and Alizarin Red $\mathrm{S}$ staining of these sheets in cell-free conditions (Fig. 7). Crystallization of hydroxyapatite on the composite surface and/or osteopontin-rich extracellular matrix would attract osteoclast progenitors similarly to natural bone. Alternatively, PLGA/A2 composite surfaces promoted the attachment of osteoprogenitors through, i.e., enhanced BMP-2 signaling and these in turn signaled for osteoclast development. Regardless of the mechanisms, our present data support the concept that calcium-rich bioactive glasses may be a key component of PLGA-based composites where the requirement is to support bone remodeling.

An exciting new finding of this work is the ability of PLGA/S-BG composites to support BMP-mediated osteogenesis of bone marrow-derived human MSC in standard, serum-containing medium. BMP-2 was previously shown to be ineffective at elevating ALP activity in MSC derived from bone marrow of adult patients and cultured on TCP in these same culture conditions. ${ }^{30}$ Recent attempts to improve the osteogenic response of human MSC to BMP-2 and/or Dex by culturing these cells on pure $45 \mathrm{~S} 5$ bioactive glass also did not have much success. ${ }^{35}$ In this study, culturing human MSC on the PLGA/A2-33 composite sheets significantly increased ALP/cell levels compared to standard TCP. A similar tendency was observed for PLGA/S2-33 composites. PLGA/A2-21 sheets also enhanced BMP-2 mRNA expression of hMSC. Furthermore, all the PLGA/S2 composites studied enhanced cell-mediated calcification of extracellular matrix $(\mathrm{ECM})$ in either BMP-2 or Dex-mediated osteogenic conditions. We compared Alizarin Red S staining of composites in parallel cultures with and without cells. Increased Alizarin Red S staining was apparent for PLGA/S2 composite sheets that were used as growth surfaces for bone marrow-derived human MSC, regardless of cell treatments. Similar data were obtained for PLGA/A2-12 composites, but high staining intensity of composites containing higher proportion of $\mathrm{A} 2 \mathrm{~S}-\mathrm{BG}$ in cell-free conditions did not allow us to quantify the effect. In contrast, pure PLGA did not support cell-mediated calcification of ECM in either BMP-2 or Dex-enriched osteogenic medium despite some ability of these cells to calcify ECM with Dex on TCP (data not shown). Since PLGA/S2 composites showed moderate surface activity and/or bioactivity in cell-free solutions, we suggest these composite features may be a key to promotion of the BMP-mediated osteogenic response of cells in vitro.

The potential for the presently studied composite materials to be used as a bone graft substitute or tissue engineering scaffold is further supported by our 3D culture studies, despite they were done with another cell population of known osteoblastic properties (i.e., MG-63 cell line) (Fig. 9). Cell distributions were comparable within all studied constructs and comparable numbers of live cells were detected after 2-week MG-63 culture in all studied 3D scaffolds. However, MG-63 cells cultured in 3D PLGA-BG composites produced significantly higher levels of collagen and calcium suggesting osteoinductive properties of composite scaffolds.

\section{CONCLUSIONS}

Our present studies have shown that it is possible to produce a wide variety of bioactive composite materials made of poly(L-lactide-co-glycolide) and solgel derived bioactive glass. These composites differ in mechanical performance, wettability, degradation kinetics, bioactivity, and biological properties depending on the content and composition of bioactive glass. The composites made of PLGA and silica-rich S2 bioactive glass exhibit: (i) similar wettability as pure PLGA, (ii) slow degradation kinetics, manifested by neutral $\mathrm{pH}$ and stable conductivity values of the incubation medium, (iii) good biological properties manifested by enhanced human bone marrow cell proliferation and osteoinductive properties in both 2D and 3D culture systems. The composites made of PLGA and calcium-rich A2 bioactive glass exhibit: (i) high bioactivity manifested by crystallization of hydroxyapatite and (ii) ability to promote both osteoblast and osteoclast formation. Thus, the composites made of PLGA and sol-gel derived bioactive glasses should find wide applications where a mechanically strong osteoinductive material is required for bone tissue engineering and bone tissue regeneration.

\section{ACKNOWLEDGMENTS}

We would like to thank Dr P. Dobrzyński from the Centre of Polymer and Carbon Materials, Polish Academy of Sciences, Zabrze, Poland, for synthesizing polymers used in this work and Mr. M. Dworak (AGH, Department of Biomaterials, Krakow, Poland) for his help in mechanical tests. The authors thank 
Prof. T. Niedźwiedzki, the Head of the Polytrauma, Orthopedic and Neuroorthopedic Department of the Rydygier Hospital in Krakow, for procuring human bone marrow samples. We also want to thank Joss Atkinson of the University of Sheffield for providing MTS calibration data. Funding for this study was provided in part by MIRG-CT-2007-046479 grant within EC 6FP (AMO), Polish Ministry of Science and Education matching funds 465/6.PRUE/2007/7 (AMO), Polish State Committee for Scientific Research grants no. NN401 006135 (AMO), no. NN508 476338 (ML), no. NN 507280736 (EP), and no. 11.11.60.365 (ML).

\section{OPEN ACCESS}

This article is distributed under the terms of the Creative Commons Attribution Noncommercial License which permits any noncommercial use, distribution, and reproduction in any medium, provided the original author(s) and source are credited.

\section{REFERENCES}

${ }^{1}$ Aitken, C. J., J. M. Hodge, and G. C. Nicholson. Adenoviral down-regulation of osteopontin inhibits human osteoclast differentiation in vitro. J. Cell. Biochem. 93:896903, 2004.

${ }^{2}$ AlGhamdi, A. S., O. Shibly, and S. G. Ciancio. Osseous grafting part I: autografts and allografts for periodontal regeneration - a literature review. J. Int. Acad. Periodontol. 12:34-38, 2010 .

${ }^{3}$ Boccaccini, A. R., and V. Marquet. Bioresorbable and bioactive polymer/Bioglass ${ }^{\circledR}$ composites with tailored pore structure for tissue engineering applications. Compos. Sci. Technol. 63:2417-2429, 2003.

${ }^{4}$ Boccaccini, A. R., J. A. Roether, L. L. Hench, V. Maquet, and R. Jerome. A composites approach to tissue engineering. Ceram. Eng. Sci. Proc. 23:805-816, 2002.

${ }^{5}$ Cholewa-Kowalska, K., J. Kokoszka, M. Łaczka, Ł. Niedźwiedzki, W. Madej, and A. M. Osyczka. Gel-derived bioglass as a compound of hydroxyapatite composites. Biomed. Mater. 4:1-11, 2009.

${ }^{6}$ Cholewa-Kowalska, K., M. Lączka, and A. Osyczka. Surface phenomena on gel-derived bioceramics-chemical and clinical aspects. Key Eng. Mater. 206-213:1559-1562, 2002.

${ }^{7}$ Cullinane, D. M., and K. T. Salisbury. Biomechanics. In: Bone Tissue Engineering, edited by J. O. Hollinger, T. A. Einhorn, B. A. Doll, and C. Sfeir. Boca Raton: CRC Press, 2005, pp. 245-276.

${ }^{8}$ Day, R. M., V. Maquet, A. R. Boccaccini, R. Jérôme, and A. Forbes. In vitro and in vivo analysis of macroporous biodegradable poly(d,l-lactide-co-glycolide) scaffolds containing bioactive glass. J. Biomed. Mater. Res. 75A:778787, 2005.

${ }^{9}$ Diefenderfer, D. L., A. M. Osyczka, J. P. Garino, and P. S. Leboy. Regulation of BMP-induced transcription in cultured human bone marrow stromal cells. J. Bone Joint Surg. Am. 85 A(Suppl. 3):19-28, 2003.

${ }^{10}$ Diefenderfer, D. L., A. M. Osyczka, G. C. Reilly, and P. S. Leboy. BMP responsiveness in human mesenchymal stem cells. Connect. Tissue Res. 44(Suppl. 1):305-311, 2003.

${ }^{11}$ Dobrzyński, P., J. Kasperczyk, H. Janeczek, and M. Bero. Synthesis of biodegradable copolymers with the use of low toxic zirconium compounds. 1. Copolymerization of glycolide with L-lactide initiated by $\operatorname{Zr}(\mathrm{Acac})_{4}$. Macromolecules 34:5090-5103, 2001.

${ }^{12}$ Douglas, T., E. Pamula, D. Hauk, J. Wiltfang, S. Sivananthan, E. Sherry, and P. H. Warnke. Porous polymer/ hydroxyapatite scaffolds: characterization and biocompatibility investigations. J. Mater. Sci. Mater. Med. 20:19091915, 2009.

${ }^{13}$ El-Ghannam, A. Bone reconstruction: from bioceramics to tissue engineering. Expert Rev. Med. Devices 2:87-101, 2005.

${ }^{14}$ Geblinger, D., L. Addadi, and B. Geiger. Nano-topography sensing by osteoclasts. J. Cell Sci. 123:1503-1510, 2010.

${ }^{15}$ Graham, S. M., A. Leonidou, N. Aslam-Pervez, A. Hamza, P. Panteliadis, M. Heliotis, A. Mantalaris, and E. Tsiridis. Biological therapy of bone defects: the immunology of bone allo-transplantation. Expert Opin. Biol. Ther. 10:885901,2010

${ }^{16}$ ISO 10993-13. Biological evaluation of medical devices Part 13: Identification and quantification of degradation products from polymeric medical devices, 1998.

${ }^{17}$ Karpov, M., M. Laczka, P. S. Leboy, and A. M. Osyczka. Sol-gel bioactive glasses support both osteoblast and osteoclast formation from human bone marrow cells. J. Biomed. Mater. Res. 84A:718-726, 2008.

${ }^{18}$ Kokubo, T., H.-M. Kim, and M. Kawashita. Novel bioactive materials with different mechanical properties. Biomaterials 24:2161-2175, 2003.

${ }^{19}$ Laczka, M., K. Cholewa-Kowalska, K. Kulgawczyk, M. Klisch, and W. Mozgawa. Structural examinations of gel-derived materials of the $\mathrm{CaO}-\mathrm{P}_{2} \mathrm{O}_{5}-\mathrm{SiO}_{2}$ system. J. Mol. Str. 511-512:223-231, 1999.

${ }^{20}$ Łaczka-Osyczka, A., M. Łączka, S. Kasugai, and K. Ohya. Behaviour of bone marrow cells cultured on three different coatings of gel-derived bioactive glass-ceramics at early stages of cell differentiation. J. Biomed. Mater. Res. 42: 433-442, 1998.

${ }^{21}$ Lian, J. B., G. S. Stein, A. Javed, A. J. van Wijnen, J. L. Stein, M. Montecino, M. Q. Hassan, T. Gaur, C. J. Lengner, and D. W. Young. Networks and hubs for the transcriptional control of osteoblastogenesis. Rev. Endocr. Metab. Disord. 7:1-16, 2006.

${ }^{22}$ Lu, H. H., A. Tang, S. C. Oh, J. P. Spalazzi, and K. Dionisio. Compositional effects on the formation of a calcium phosphate layer and the response of osteoblast-like cells on polymer-bioactive glass composites. Biomaterials 26:6323-6334, 2005.

${ }^{23}$ Lü, J. M., X. Wang, C. Marin-Muller, H. Wang, P. H. Lin, Q. Yao, and C. Chen. Current advances in research and clinical applications of PLGA-based nanotechnology. Expert Rev. Mol. Diagn. 9:325-341, 2009.

${ }^{24}$ Mahony, O., and J. R. Jones. Porous bioactive nanostructured scaffolds for bone regeneration: a sol-gel solution. Nanomedicine 3:233-245, 2008.

${ }^{25}$ Maquet, V., A. R. Boccaccini, L. Pravata, I. Notingher, and R. Jerome. Porous poly( $\alpha$-hydroxyacid)/Bioglass composite scaffolds for bone tissue engineering. I: preparation 
and in vitro characterization. Biomaterials 25:4185-4194, 2004.

${ }^{26}$ Misra, S. K., D. Mohn, T. J. Brunner, W. J. Stark, S. E. Philip, I. Roy, V. Salih, J. C. Knowles, and A. R. Boccaccini. Comparison of nanoscale and microscale bioactive glass on the properties of $\mathrm{P}(3 \mathrm{HB}) /$ Bioglass composites. Biomaterials 29:1750-1761, 2008.

${ }^{27}$ Niedzielski, K., R. Sindut, K. Cholewa-Kowalska, M. Laczka, and J. Kokoszka. New generation bioactive glass-ceramics as a substitute of bone-in vivo study. Eng. Biomater. 67-68:48-51, 2007.

${ }^{28}$ Niemiel, T., H. Niiranen, M. Kellomaki, and P. Tormala. Self-reinforced composites of bioabsorbable polymer and bioactive glass with different bioactive glass contents. Part I: initial mechanical properties and bioactivity. Acta Biomater. 1:235-242, 2005.

${ }^{29}$ Osyczka, A. M., D. L. Diefenderfer, G. A. Bhargave, and P. S. Leboy. Different effects of BMP-2 on marrow stromal cells from human and rat bone. Cells Tissues Organs 176(1-3):109-119, 2004.

${ }^{30}$ Osyczka, A. M., and P. S. Leboy. Bone morphogenetic protein regulation of early osteoblast genes in human marrow stromal cells is mediated by extracellular signalregulated kinase and phosphatidylinositol 3-kinase signaling. Endocrinology 146:3428-3437, 2005.

${ }^{31}$ Pamula, E., M. Blazewicz, C. Paluszkiewicz, and P. Dobrzynski. FTIR study of degradation products of aliphatic polyesters-carbon fibres composites. J. Mol. Str. 596:69-75, 2001.

${ }^{32}$ Pamula, E., E. Filova, L. Bacakova, V. Lisa, and D. Adamczak. Resorbable polymeric scaffolds for bone tissue engineering: the influence of their microstructure on the growth of human osteoblast-like MG 63 cells. J. Biomed. Mater. Res. 89A:432-443, 2009.

${ }^{33}$ Pamula, E., and E. Menaszek. In vitro and in vivo degradation of poly(L-lactide-co-glycolide) films and scaffolds. J. Mater. Sci. Mater. Med. 19:2063-2070, 2008.

${ }^{34}$ Porter, J. R., T. T. Ruckh, and K. C. Popat. Bone tissue engineering: a review in bone biomimetics and drug delivery strategies. Biotechnol. Prog. 25:1539-1560, 2009.

${ }^{35}$ Reilly, G. C., S. Radin, A. T. Chen, and P. Ducheyne. Differential alkaline phosphatase responses of rat and human bone marrow derived mesenchymal stem cells to 45S5 bioactive glass. Biomaterials 28:4091-4097, 2007.
${ }^{36}$ Rezwan, K., Q. Z. Chen, J. J. Blaker, and A. R. Boccaccini. Review. Biodegradable and bioactive porous polymer/ inorganic composite scaffolds for bone tissue engineering. Biomaterials 27:3413-3431, 2006.

${ }^{37}$ Rickard, D. J., T. A. Sullivan, B. J. Shenker, P. S. Leboy, and I. Kazhdan. Induction of rapid osteoblast differentiation in rat bone marrow stromal cell cultures by dexamethasone and BMP-2. Dev. Biol. 161:218-228, 1994.

${ }^{38}$ Rittling, S. R., H. N. Matsumoto, M. D. McKee, A. Nanci, X. R. An, K. E. Novick, A. J. Kowalski, M. Noda, and D. T. Denhardt. Mice lacking osteopontin show normal development and bone structure but display altered osteoclast formation in vitro. J. Bone Miner. Res. 13:1101$1111,1998$.

${ }^{39}$ Roether, J. A., A. R. Boccaccini, L. L. Hench, V. Maquet, S. Gautier, and R. Jerome. Development and in vitro characterisation of novel bioresorbable and bioactive composite materials based on polylactide foams and bioglass for tissue engineering applications. Biomaterials 23:3871-3878, 2002.

${ }^{40}$ Schwartz, Z., E. Nasazky, and B. D. Boyan. Surface microtopography regulates osteointegration: the role of implant surface microtopography in osteointegration. Alpha Omega. 98:9-19, 2005.

${ }^{41}$ Wu, C., Y. Ramaswamy, Y. F. Zhu, R. Zheng, R. Appleyard, A. Howard, and H. Zreigat. The effect of mesoporous bioactive glass on the physiochemical, biological and drugrelease properties of poly(dl-lactide-co-glycolide) films. Biomaterials 30:2199-2208, 2009.

${ }^{42}$ Yao, J., S. Radin, S. Leboy, and P. Ducheyne. The effect of bioactive glass content on synthesis and bioactivity of composite poly(lactic-co-glycolic acid)/bioactive glass substrate for tissue engineering. Biomaterials 26:1935-1943, 2005.

${ }^{43}$ Yao, J., S. Radin, G. Reilly, P. S. Leboy, and P. Ducheyne. Solution-mediated effect of bioactive glass in poly (lacticco-glycolic acid)-bioactive glass composites on osteogenesis of marrow stromal cells. J. Biomed. Mater. Res. 75A:794-801, 2005.

${ }^{44}$ Zhang, K., Y. Wang, M. A. Hillmyer, and L. F. Francis. Processing and properties of porous poly(L-lactide)/bioactive glass composites. Biomaterials 25:2489-2500, 2004. 